\title{
A Numerical Study of the Direct Contact Condensation on a Horizontal Surface
}

\section{M.M. Hasan}

Lewis Research Center

Cleveland, Ohio

and

C.S. Lin

Analex Corporation

Fairview Park, Ohio

Prepared for the

26th Thermophysics Conference

sponsored by the American Institute of Aeronautics and Astronautics

Honolulu, Hawaii, June 24-26, 1991 


\title{
A NUMERICAL STUDY OF THE DIRECT CONTACT CONDENSATION \\ ON A HORIZONTAL SURFACE
}

\author{
M.M. Hasan \\ National Aeronautics and Space Administration \\ Lewis Research Center \\ Cleveland, Ohio 44135 \\ and \\ C. S. Lin \\ Analex Corporation \\ Fairview Park, Ohio 44126
}

\begin{abstract}
$\underline{\text { Abstract }}$
This paper presents the results of a numerical study of the direct contact condensation on a slowly moving horizontal liquid surface. The geometrical configuration and the input conditions used to obtain numerical solutions are representative to those of experiments of Celata et al. ${ }^{7}$ The effects of Prandtl number (Pr), inflow Reynolds number $\left(\mathrm{Re}_{\mathrm{in}}\right)$, and $\mathrm{Richardson}$ number $(\mathrm{Ri})$ on the condensation rate are investigated. Numerical predictions of condensation rate for laminar flow are in good agreement with experimental data. The effect of buoyancy on the condensation rate is characterized by Richardson number. A correlation based on the numerical solutions is developed to predict the average condensation Nusselt number in terms of Richardson number, Peclet number, and inflow Reynolds number.
\end{abstract}

\section{Nomenclature}

A surface area

Ar aspect ratio, $\mathrm{H} / \mathrm{D}$

B tank to jet diameter ratio, D/d

$\mathrm{C}_{\mathrm{p}} \quad$ specific heat at constant pressure

d,D jet diameter, tank diameter

g gravitational acceleration

$\mathrm{H} \quad$ liquid height

$h_{c} \quad$ heat transfer coefficient at the interface $h_{c}=k(\partial T / \partial x)_{s} /\left(T_{s}-T_{i n}\right)$

$\mathrm{h}_{\mathrm{fg}} \quad$ latent heat of condensation

Ja Jakob number, $C_{p}\left(T_{s}-T_{i n}\right) / h_{f g}$

k thermal conductivity

$\mathrm{m}_{\mathrm{c}} \quad$ local condensation mass flux

$\mathrm{Nu}_{\mathrm{c}} \quad$ Condensation Nusselt number, $\mathrm{h}_{\mathrm{c}} \mathrm{D} / \mathrm{k}$

$\mathrm{Nu}_{c o}$ local condensation Nusselt number for $\mathrm{Ri}=0$ 


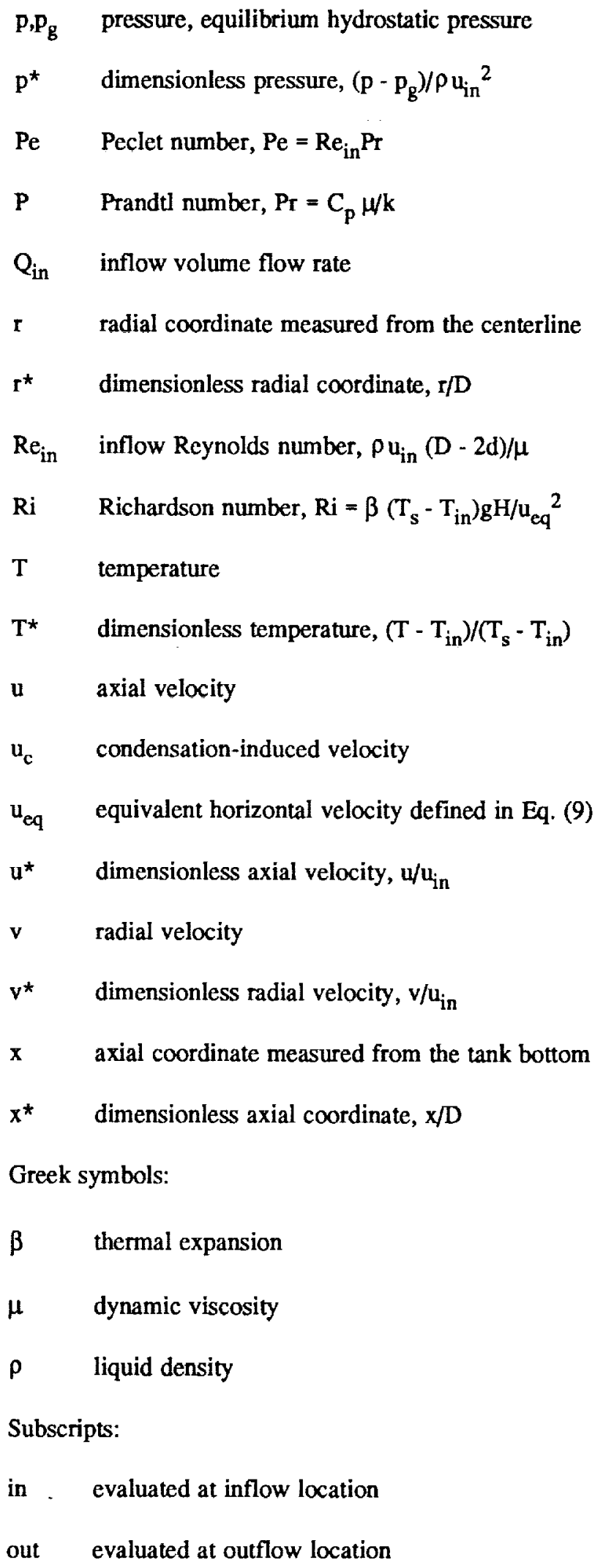


evaluated at condensation condition

Introduction

The pressure control of cryogenic tanks during the on-orbit storage and transfer of cryogenic liquids, such as hydrogen and nitrogen under microgravity conditions is a challenging problem. A preferred method of tank pressure control in space environment is the use of a thermodynamic vent system along with fluid mixing. ${ }^{1,2}$ Direct contact condensation of vapor on the liquid surface plays a central role in such a pressure control system.

The authors ${ }^{3-5}$ numerically obtained the condensation rate as a function of the associated system and flow parameters in a laminar axial jet-induced mixing tank. One important conclusion of these investigations is that the interface condensation rate could be simply determined by the jet volume flow rate and jet subcooling, ${ }^{3,4}$ for conditions where buoyancy effects are negligible. The effects of buoyancy on the condensation rate can be characterized in terms of Richardson number. ${ }^{5,6}$ Numerical predictions ${ }^{5}$ show that in a laminar jet induced mixing system the condensation rate is significantly reduced for higher values of Richardson number. The authors ${ }^{3-5}$ are not aware of any experimental data of the vapor condensation rate on a liquid surface in a laminar jet induced mixing system. Therefore, the numerical predictions could not be compared with experiments.

Recently, Celata et al. ${ }^{7}$ conducted an experiment and measured the condensation rate of saturated steam on a horizontal, subcooled, slowly moving water surface. The range of liquid flow rates covered in the experiment encompasses the laminar and the turbulent flow regimes. A theoretical model that contains three empirical constants was developed to predict the interfacial heat transfer coefficient. However, the description of the transport phenomena in the near-interface region was not presented in the paper. Also, the effects of fluid properties, buoyancy, and mass flow rate that can generally be expressed in terms of Prandtl number, Richardson number and Reynolds number were not shown explicitly. The objective of this study is to obtain a numerical solution of Celata's experiment, clarify the effects of the pertinent dimensionless parameters on the condensation rate, and compare the prediction with the measurements. ${ }^{7}$ A brief description of Celata's experiment and its adaptation to the present numerical simulation is presented in the following sections.

\section{The Physical Problem}

The physical system and the coordinates used to analyze the problem are similar to those of Ref. 7 and are shown in Fig. 1. A circular cylindrical tank of diameter D contains liquid with a filling height $H$. A uniform annular inflow of velocity $u_{\text {in }}$ is introduced into the tank from the outer portion of the tank bottom toward the liquid-vapor interface. Liquid is simultaneously withdrawn from the central portion of the tank at the same volume flow rate $Q_{i n}$ such that the liquid fill level is kept constant. The circular liquid outflow has a diameter, $d$. The tank pressure is maintained constant resulting in a constant interface saturation temperature $T_{s}$. The inflow liquid is subcooled and has a constant and uniform temperature $T_{i n}$. The outflow region is assumed to have zero temperature gradient.

The energy balance at the interface yields the following relation between condensation mass flux and heat transfer at the interface

$$
\overline{\mathrm{m}}_{\mathrm{c}} \mathrm{h}_{\mathrm{fg}} \mathrm{A}_{\mathrm{s}}=\int \mathrm{m}_{\mathrm{c}} \mathrm{h}_{\mathrm{fg}} \mathrm{dA} \mathrm{A}_{s}=\int\left(\mathrm{k} \frac{\partial \mathrm{T}}{\partial \mathrm{x}}\right)_{\mathrm{s}} \mathrm{dA}
$$

where $\bar{m}_{c}$ is the average mass condensation flux over the interface area $A_{s}$. The average condensation heat tranșfer coefficient $\left(\overline{\mathrm{h}}_{\mathrm{c}}\right)$ and average condensation Nusselt number $\left(\overline{\mathrm{Nu}}_{\mathrm{c}}\right)$ over the interface can be defined as

$$
\overline{\mathrm{h}}_{\mathrm{c}}=\frac{\overline{\mathrm{m}}_{\mathrm{c}} \mathrm{h}_{\mathrm{fg}}}{\left(\mathrm{T}_{\mathrm{s}}-\mathrm{T}_{\mathrm{in}}\right)}
$$

and 


$$
\overline{\mathrm{Nu}}_{\mathrm{c}}=\frac{\overline{\mathrm{h}}_{\mathrm{c}} \mathrm{D}}{\mathrm{k}}=\frac{\overline{\mathrm{m}}_{\mathrm{c}} \mathrm{h}_{\mathrm{fg}} \mathrm{D}}{\mathrm{k}\left(\mathrm{T}_{\mathrm{s}}-\mathrm{T}_{\mathrm{in}}\right)}
$$

\section{Mathematical Formulation}

The steady-state, incompressible Navier-Stokes equations are employed to solve the present problem. The gravity is acting in the vertical negative- $x$ direction and the effect of buoyancy is accounted for by using the Boussinesq approximation. The dimensionless form of the governing equations are expressed as:

$$
\begin{aligned}
& \frac{\partial \mathrm{u}^{*}}{\partial \mathrm{x}^{*}}+\frac{\partial \mathrm{r}^{*} \mathrm{v}^{*}}{\mathrm{r}^{*} \partial \mathrm{r}^{*}}=0
\end{aligned}
$$

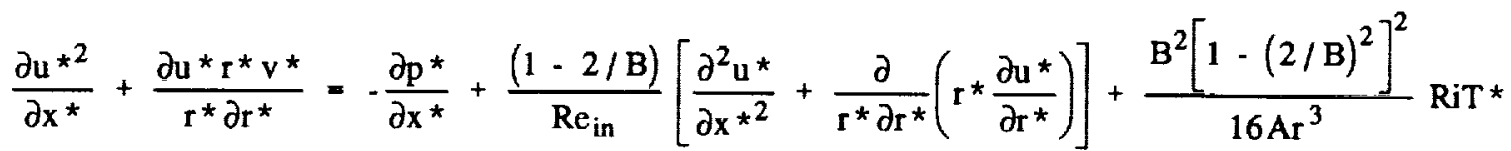

$$
\begin{aligned}
& \frac{\partial \mathrm{u}^{*} \mathrm{v}^{*}}{\partial \mathrm{x}^{*}}+\frac{\partial \mathrm{r}^{*} \mathrm{v}^{2}}{\mathrm{r}^{*} \partial \mathrm{r}^{*}}=\frac{\partial \mathrm{p}^{*}}{\partial \mathrm{r}^{*}}-\frac{(1-2 / \mathrm{B})}{\operatorname{Re}_{\mathrm{in}}} \frac{\mathrm{v}^{*}}{\mathrm{r}^{*^{2}}}+\frac{(1-2 / \mathrm{B})}{\operatorname{Re}_{\mathrm{in}}}\left[\frac{\partial^{2} \mathrm{v}^{*}}{\partial \mathrm{x}^{*^{2}}} \frac{\partial}{\mathrm{r}^{*} \partial \mathrm{r}^{*}}\left(\mathrm{r}^{*} \frac{\partial \mathrm{v}^{*}}{\partial \mathrm{r}^{*}}\right)\right] \\
& \frac{\partial \mathrm{u}^{*} \mathrm{~T}^{*}}{\partial \mathrm{x}^{*}}+\frac{\partial \mathrm{r}^{*} \mathrm{v}^{*} \mathrm{~T}^{*}}{\mathrm{r}^{*} \partial \mathrm{r}^{*}}=\frac{(1-2 / \mathrm{B})}{\mathrm{Re}_{\mathrm{in}} \operatorname{Pr}}\left[\frac{\partial^{2} \mathrm{~T}^{*}}{\partial \mathrm{x}^{* 2}}+\frac{\partial}{\mathrm{r}^{*} \partial \mathrm{r}^{*}}\left(\mathrm{r}^{*} \frac{\partial \mathrm{T}^{*}}{\partial \mathrm{r}^{*}}\right)\right]
\end{aligned}
$$

where the parameter $\mathrm{B}$, aspect ratio $\mathrm{Ar}$, Prandtl number $\mathrm{Pr}$, inflow Reynolds number $\mathrm{Re}_{\mathrm{in}}$, and Richardson number $\mathrm{Ri}$ are defined as

$$
B=D / d, \quad A r=H / D, \quad \operatorname{Pr}=C_{p} \mu / k, \quad R_{\text {in }}=\rho u_{\text {in }}(D-2 d) / \mu, \quad R i=\beta\left(T_{s}-T_{\text {in }}\right) g H / u_{e q} 2
$$

Other variables and dimensionless parameters are defined in the nomenclature. It is to be noted that in the definition of Richardson number $(\mathrm{Ri}), \mathrm{u}_{\mathrm{eq}}$ is defined as an equivalent horizontal velocity with which the flow passing through the opening between the interface and the outflow location has the same volume flow rate as subcooled inflow, i.e.,

$$
\pi \mathrm{dHu}_{\text {eq }}=\mathrm{A}_{\mathrm{in}} \mathrm{u}_{\mathrm{in}}
$$
used:

The boundary conditions are required to solve Eqs. (4) to (7). At the centerline, the symmetric conditions are

$$
\mathrm{v}^{*}=0, \quad \frac{\partial \mathrm{u}^{*}}{\partial \mathrm{r}^{*}}=\frac{\partial \mathrm{T}^{*}}{\partial \mathrm{r}^{*}}=0 \quad \text { at } \mathrm{r}^{*}=0
$$

At the solid walls, the no-slip and adiabatic conditions are employed:

$$
\mathrm{u}^{*}=\mathrm{v}^{*}=0, \frac{\partial \mathrm{T}^{*}}{\partial \mathrm{x}^{*}}=\frac{\partial \mathrm{T}^{*}}{\partial \mathrm{r}^{*}}=0 \text { at walls. }
$$

The free surface is assumed to be flat (wave free) and shear free. The condensation-induced velocity at the interface, $u_{c}$, is equal to

$$
\mathrm{u}_{\mathrm{c}}=\mathrm{m}_{\mathrm{c}} / \rho
$$

and is generally negligibly small compared with surface velocity. ${ }^{3}$ The temperature of the interface is kept constant at $T_{s}$. Thus, the boundary conditions applied at the interface are,

$$
\mathrm{u}^{*}=0, \frac{\partial \mathrm{v}^{*}}{\partial \mathrm{x}^{*}}=0, \mathrm{~T}^{*}=1 \text { at } \mathrm{x}^{*}=\mathrm{H} / \mathrm{D}
$$

For the inflow, the velocity and temperature are assumed to be uniform:

$$
\mathrm{u}^{*}=1, \mathrm{v}^{*}=0, \mathrm{~T}^{*}=0 \text { at the inflow location. }
$$

In order to maintain liquid level constant, the liquid withdrawn at the central nozzle should have a volume flow rate equal to the sum of inflow volume flow rate $Q_{\text {in }}$ plus induced interfacial condensation flow rate. Since $u_{c}$ is assumed negligibly small, the outflow volume flow rate is approximately equal to the inflow volume flow rate. 
Assuming the outflow velocity is uniform, the outflow velocity is obtained by $\mathrm{Q}_{\mathrm{in}} / \mathrm{A}_{\text {out }}$. At the outflow location a zero temperature gradient is assumed. Thus,

$$
u^{*}=-A_{\text {in }} / A_{\text {out }}, v^{*}=0, \frac{\partial T^{*}}{\partial x^{*}}=0 \text { at outflow location. }
$$

Based on the above dimensionless variables, the average heat transfer coefficient $\bar{h}_{c}$ becomes

$$
\overline{\mathrm{h}}_{\mathrm{c}}=8(\mathrm{k} / \mathrm{D}) \int_{0}^{0.5}\left(\frac{\partial \mathrm{T}^{*}}{\partial \mathrm{x}^{*}}\right)_{s} \mathrm{r}^{*} \mathrm{dr} \mathrm{r}^{*}
$$

and the average condensation Nusselt number is

$$
\overline{\mathrm{Nu}}_{\mathrm{c}}=8 \int_{0}^{0.5}\left(\frac{\partial \mathrm{T}^{*}}{\partial \mathrm{x}^{*}}\right)_{\mathrm{s}} \mathrm{r}^{*} \mathrm{dr} \mathrm{r}^{*}
$$

\section{Numerical Method of Solutions}

Equations (4) to (7) are numerically solved by a finite-difference method. The finite-difference equations are derived by integrating the differential equations over an elementary control volume surrounding a grid node appropriate for each dependent variable. ${ }^{8}$ A staggered grid system is used such that the scalar properties, $\mathrm{p}^{\star}$ and $\mathrm{T}^{*}$, are stored midway between the $u^{*}$ and $v^{*}$ velocity grid nodes. The bounded skew hybrid differencing (BSHD) is incorporated for the convective terms ${ }^{8}$ and the integrated source terms are linearized. Pressures are obtained from a predictor-corrector procedure of the Pressure Implicit Split Operator (PISO) method ${ }^{9}$ which yields the pressure change needed to procure velocity changes to satisfy mass continuity. The governing finite-difference equations are solved iteratively by the ADI method with under relaxation until the solutions are converged.

Calculations are performed with a nonuniform grid distribution with concentration of the grid nodes in the centerline, near-wall, and near-interface regions where the gradients of flow properties are expected to be large. The nonuniform grid distribution is generated by using an exponential function of Roberts' transformation. ${ }^{10}$ Several grid distributions have been tried and the grid pattern of 48 by 41 has shown to give reasonably gridindependent solutions of interface quantities. Calculations are performed on a CRAY-XMP computer located at NASA Lewis Research Center. The convergent solutions are considered to be reached when the maximum of absolute residual sums for $u^{\star}, v^{\star}$, and $T^{\star}$ variables is less than $10^{-5}$.

\section{$\underline{\text { Results and Analysis }}$}

Based on the system sketched in Fig. 1 and the associated governing equations and boundary conditions, the average condensation Nusselt number can be expressed as

$$
\overline{\mathrm{Nu}}_{\mathrm{c}}=\mathrm{f}\left(\mathrm{B}, \mathrm{Ar}, \mathrm{A}_{\mathrm{in}} / \mathrm{A}_{\text {out }}, \mathrm{Pr}, \mathrm{Re}_{\mathrm{in}}, \text { and } \mathrm{Ri}\right)
$$

The geometrical configuration and the input conditions used to obtain numerical solutions are similar to those of experiments of Celata et al. ${ }^{7}$ such that quantitative comparison between the numerical solutions and experimental data can be made. Accordingly, the system parameters $\left(\mathrm{B}, \mathrm{Ar}\right.$, and $\left.\mathrm{A}_{\mathrm{in}} / \mathrm{A}_{\text {out }}\right)$ and flow parameters $\left(\mathrm{Re}_{\mathrm{in}}, \operatorname{Pr}\right.$, and Ri) are specified as

and

$$
\mathrm{B}=13.33, \mathrm{Ar}=0.075, \mathrm{~A}_{\text {in }} / \mathrm{A}_{\text {out }}=174
$$

$$
36 \leq \mathrm{Re}_{\text {in }} \leq 330,1.1 \leq \operatorname{Pr} \leq 7.1, \quad 0 \leq \mathrm{Ri} \leq 5
$$

Figure 2 shows that for $\mathrm{Ri}=0$, the average condensation Nusselt number $\overline{\mathrm{Nu}}_{c}$ is increasing with inflow Reynolds number $\left(\mathrm{Re}_{\mathrm{in}}\right)$ and Prandtl number $(\mathrm{Pr})$. A correlation based on the numerical solutions (within \pm 1 percent) to predict $\overline{\mathrm{Nu}}_{c}$ at $\mathrm{Ri}=0$ is expressed as:

$$
\overline{\mathrm{Nu}}_{\mathrm{co}}=3.27(\mathrm{Pe})^{1 / 2}
$$

where $\mathrm{Pe}$ is the Peclet number and is defined as $\mathrm{Pe}=\mathrm{Re}_{\mathrm{in}} \mathrm{Pr}$. 
The buoyancy effect is characterized by Richardson number, Ri. As Ri increases, the buoyancy impedes the subcooled liquid inflow to reach the interface, resulting in a lower condensation rate. The average condensation Nusselt number $\left(\overline{\mathrm{Nu}}_{\mathrm{c}}\right)$ as a function of Richardson number for various Peclet numbers and inflow Reynolds numbers are shown in Figs. 3 and 4, respectively, in which $\overline{\mathrm{Nu}}_{c o}$ is the average condensation Nusselt number with Ri equal to zero (no buoyancy effect). For a given inflow Reynolds number and Peclet number, the condensation rate is linearly decreasing with increasing Richardson number. The effect of buoyancy on the interface condensation rate is enhanced as Peclet number increases or inflow Reynolds number decreases. A correlation based on numerical solutions to describe the average condensation Nusselt number, when the effect of buoyancy is not negligible, is given by

$$
\overline{\mathrm{Nu}}_{\mathrm{c}}=\overline{\mathrm{Nu}}_{\mathrm{co}}\left(1-0.0062 \mathrm{RiPe} \mathrm{Re} \mathrm{in}^{-2 / 3}\right)
$$

Equation (22) predict $\overline{\mathrm{Nu}}_{\mathrm{c}}$ within \pm 5 percent of numerical solution for the range of $\operatorname{Pr}$ and $\mathrm{Re}_{\text {in }}$ covered in the present study.

The subcooled liquid inflow introduced upward from the outer portion of the tank turns radially inward to the tank centerline. The dimensionless radial velocity at the interface $\left(v_{s}^{*}\right)$ for various Richardson number is shown in Fig. 5. For $\mathbf{R i}=0, v^{\star}{ }_{s}$ is negative everywhere, implying that all subcooled liquid inflow moves toward the tank centerline. As buoyancy effect increases, i.e., $\mathrm{Ri}>0$ the radial velocity at the interface moving toward the tank centerline decreases. If the buoyancy is large enough, surface velocity in the centerline region reverses direction and moves outward toward the tank wall as shown in Fig. 5 for $\mathrm{Ri}=4.4$. This means that there may exist a small clockwise vortex region underneath the interface in the centerline region. The corresponding dimensionless temperature gradient distribution at the interface is shown in Fig. 6. Except for the outflow region near the centerline, for $\mathrm{Ri}=0$, the higher surface velocity results in higher temperature gradient over the interface area than that for $\mathrm{Ri}=4.4$. Also, for the case of zero Richardson number the flow leaves the tank at a higher temperature in the outflow region near the centerline, resulting in a lower interface temperature gradient in the centerline region. On the other hand, the clockwise vortex of subcooled liquid underneath the interface for $\mathrm{Ri}=4.4$ results in more condensation in this small confined region near the tank centerline. However, the average vapor condensation rate at the interface is higher for $\mathrm{Ri}=0$ than that for $\mathrm{Ri}>0$. Figure 7 shows the comparison between the numerical predictions and experimental data of Ref. 7 for $\operatorname{Pr}=4.37$. The agreement is very good for the inflow Reynolds number up to about 150. For $\operatorname{Pr}=4.37$, the subcooled water inflow with $\operatorname{Re}_{\text {in }}>150$ will yield Richardson number smaller than 0.5 , resulting in negligible effect of buoyancy on the interface condensation rate. However, Fig. 7 shows that the numerical solutions under-predict the condensation rate for all data with $\mathrm{Re}_{\text {in }}>150$. This may be due to the fact that for higher inflow Reynolds number the flow near the interface is turbulent. Figure 8 shows the numerical predictions (Eq. 22) and experimental data (laminar) of Ref. 7 for various Prandtl numbers are in good agreement.

\section{$\underline{\text { Conclusions }}$}

A numerical solution of the direct contact condensation on a slowly moving horizontal liquid surface is obtained. The geometrical configuration and the input conditions used are representative to those of the experiments of Ref. 7. Numerical predictions of condensation rate for laminar flow are in good agreement with experimental data. Based on the numerical solutions for the parameter ranges covered in the study, the following conclusions are made:

1. For laminar flow without buoyancy effect $(\mathrm{Ri}=0)$, the average condensation Nusselt number $\left(\overline{\mathrm{Nu}}_{\mathrm{c}}\right)$ can be predicted by Eq. (21) which shows $\overline{\mathrm{Nu}}_{\mathrm{c}}$ is linearly increasing with half power of the Peclet number $\left(\mathrm{Pe}^{1 / 2}\right)$.

2. The effect of buoyancy on the condensation rate can be described by Eq. (22). The average condensation Nusselt number is linearly decreasing with increasing Richardson number. An increase in Peclet number or a decrease in flow Reynolds number enhances the effect of buoyancy on the average condensation Nusselt number.

\section{References}

1. Aydelott, J.C., Carney, M.J., and Hochstein, J.I., "NASA Lewis Research Center Low-Gravity Fluid Management Technology Program," NASA TM-87145, 1985. 
2. Poth, L.J., and Van Hook, J.R., "Control of the Thermodynamic State of Space-Stored Cryogens by Jet Mixing," Journal of Spacecraft and Rockets, Vol. 9, No. 5, May 1972, pp. 332-336.

3. Lin, C.S., "Numerical Studies of the Effects of Jet-Induced Mixing on Liquid-Vapor Interface Condensation," Journal of Thermophysics and Heat Transfer, Vol. 5, No. 1, 1991, pp. 69-75.

4. Lin, C.S. and Hasan, M.M., "Vapor Condensation on Liquid Surface Due to Laminar Jet-Induced Mixing: The Effects of System Parameters," AIAA Paper 90-0354, Jan. 1990. (Also, NASA TM-102433.)

5. Hasan, M.M. and Lin, C.S., "Buoyancy Effects on the Vapor Condensation Rate on a Horizontal Liquid Surface," AIAA Paper 90-0353, Jan. 1990. (Also, NASA TM-102437.)

6. Brown, J.S., Khoo, B.C., and Sonin, A.A., "Rate Correlation for Condensation of Pure Vapor on Turbulent, Subcooled Liquid," International Journal of Heat and Mass Transfer, Vol. 33, No. 9, 1990, pp. 2001-2018.

7. Celata, G.P., Cumo, M., Farello, G.E., and Focardi, G., "A Theoretical Model of Direct Contact Condensation on a Horizontal Surface," International Journal of Heat and Mass Transfer, Vol. 30, No. 3, 1987, pp. 459-467.

8. Syed, S.A., Chiappetta, L.M., and Gosman, A.D., "Error Reduction Program," NASA CR-174776, 1985.

9. Issa, R.I., "Solution of Implicitly Discretised Fluid Flow Equations by Operator-Splitting," Journal of Computational Physics, Vol. 62, No. 1, 1986, pp. 40-65.

10. Roberts, G.O., "Computational Meshes for Boundary Layer Problems," Second International Conference on Numerical Methods in Fluid Dynamics, Lecture Notes in Physics, Vol. 8, M. Holt, ed., Springer-Verlag, New York, 1971, pp. 171-177.

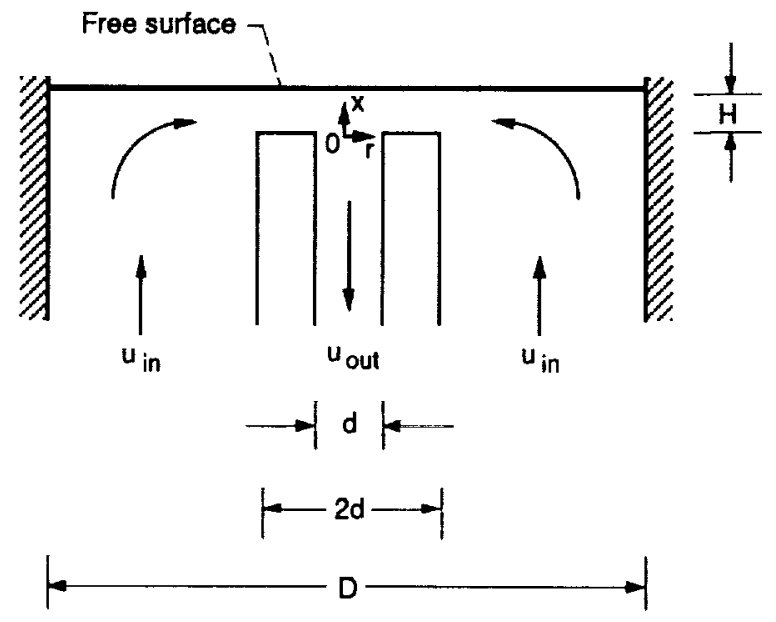

Figure 1.-Physical system and coordinates.

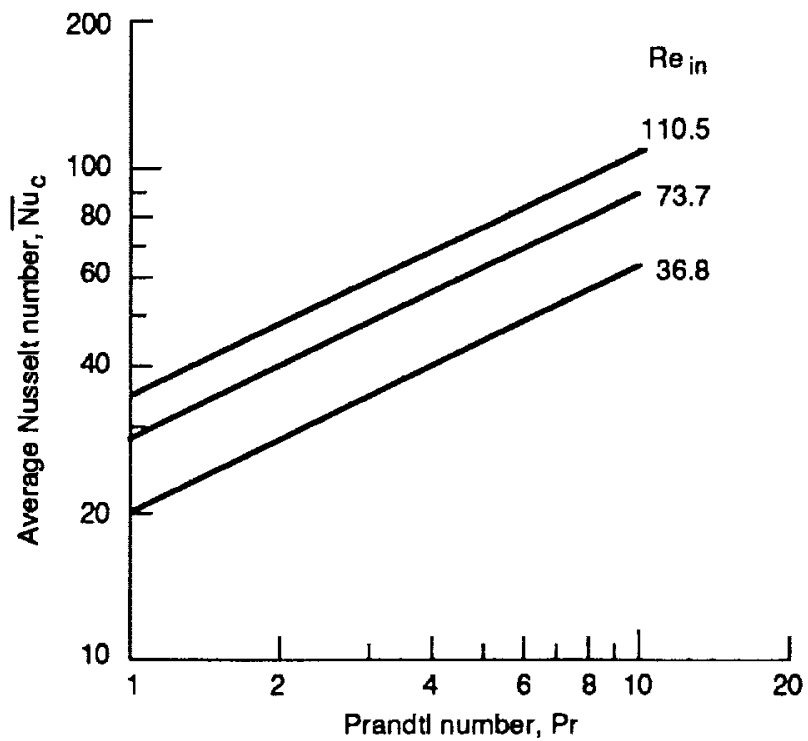

Figure 2.-Effect of Prandtl number on condensation rate for $\mathrm{Ri}=0$. 


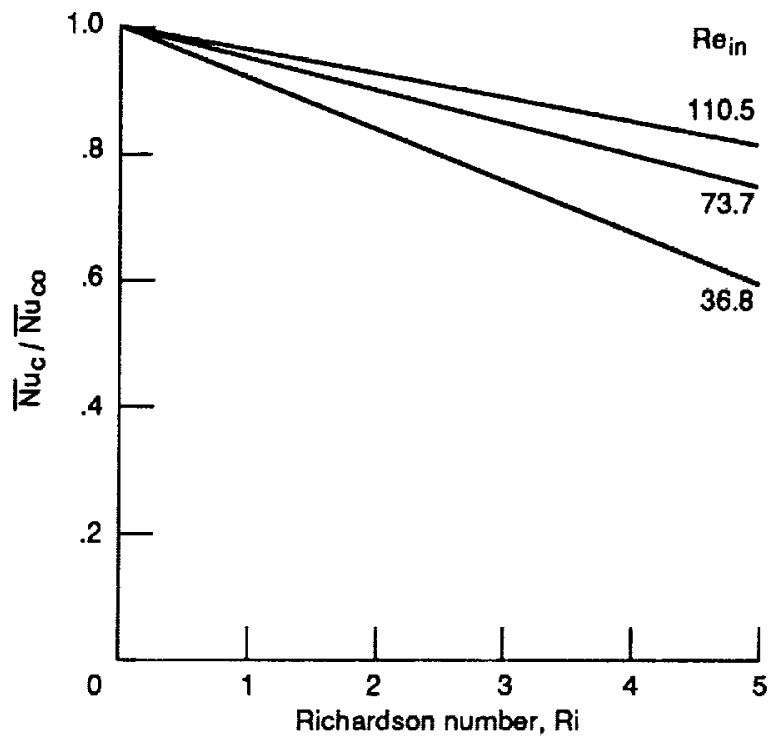

Figure 3.-Ratio of condensation Nusselt number as a function of $R i$, for $P_{e}=150$.

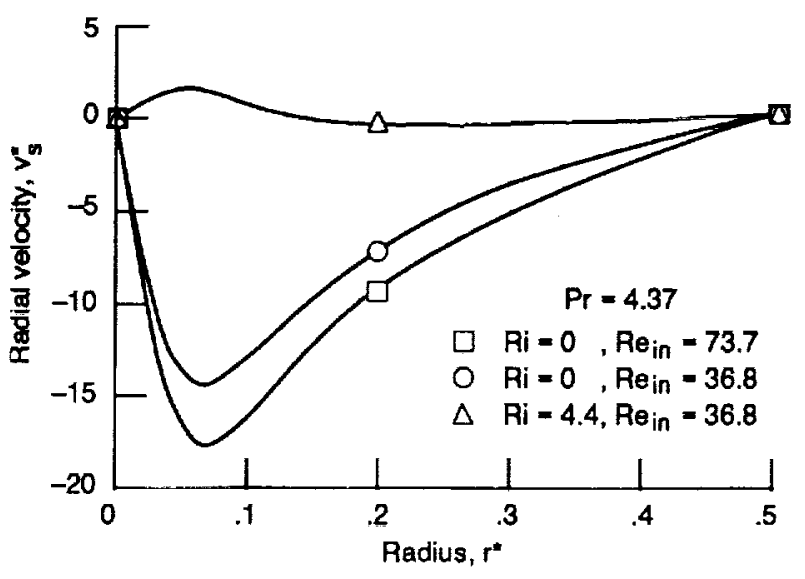

Figure 5.-Effect of Richardson number on the radial velocity at the interface.

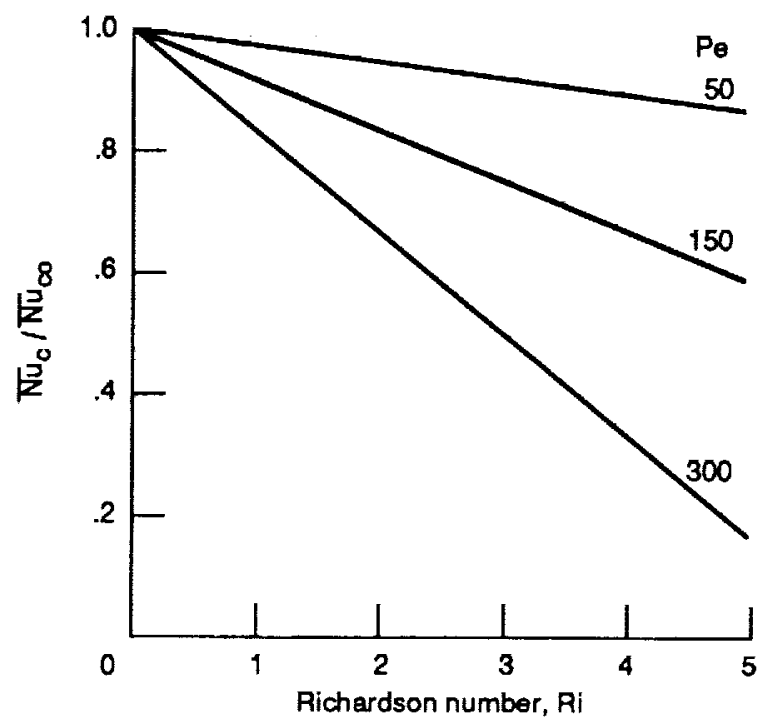

Figure 4.-Ratio of condensation Nusselt number as a function of $R i$, for $R_{e}$ in $=36.8$.

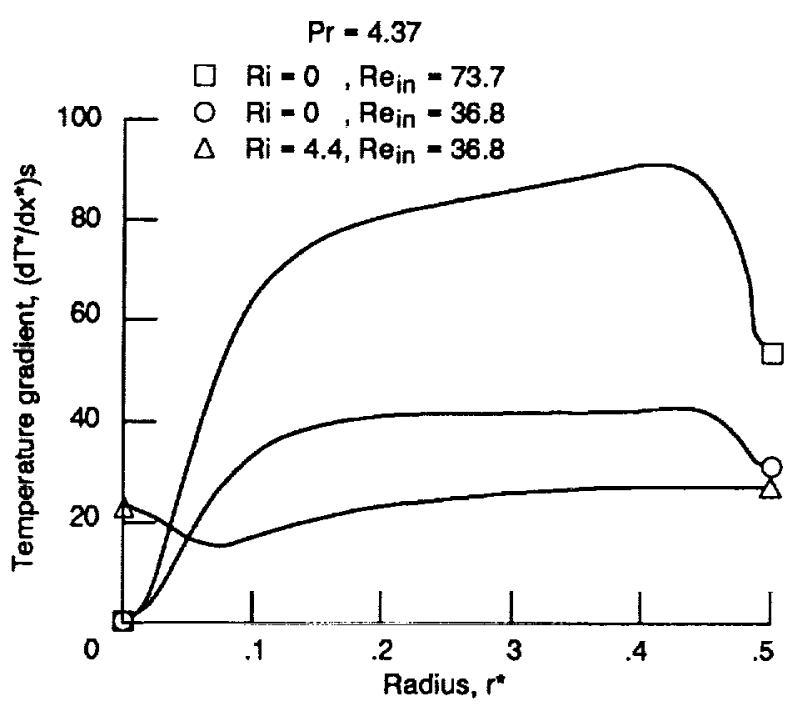

Figure 6.-Effect of Richardson number on the temperature gradients at the interface. 


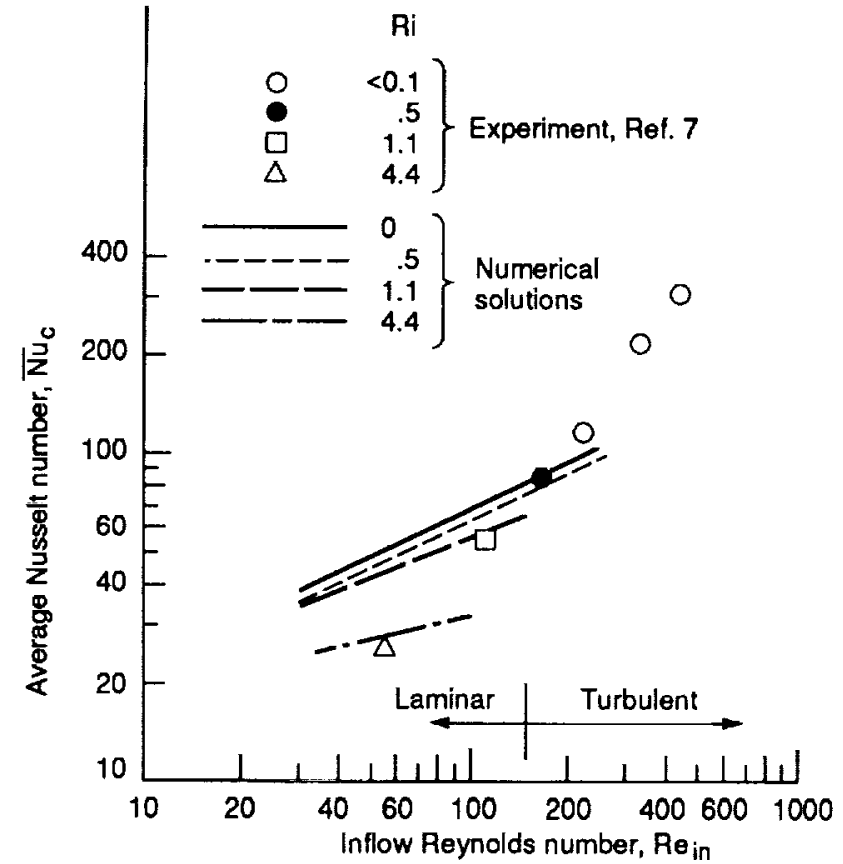

Figure 7.-Comparison with experiment for various $\mathrm{Ai}$, for $\operatorname{Pr}=4.37$.

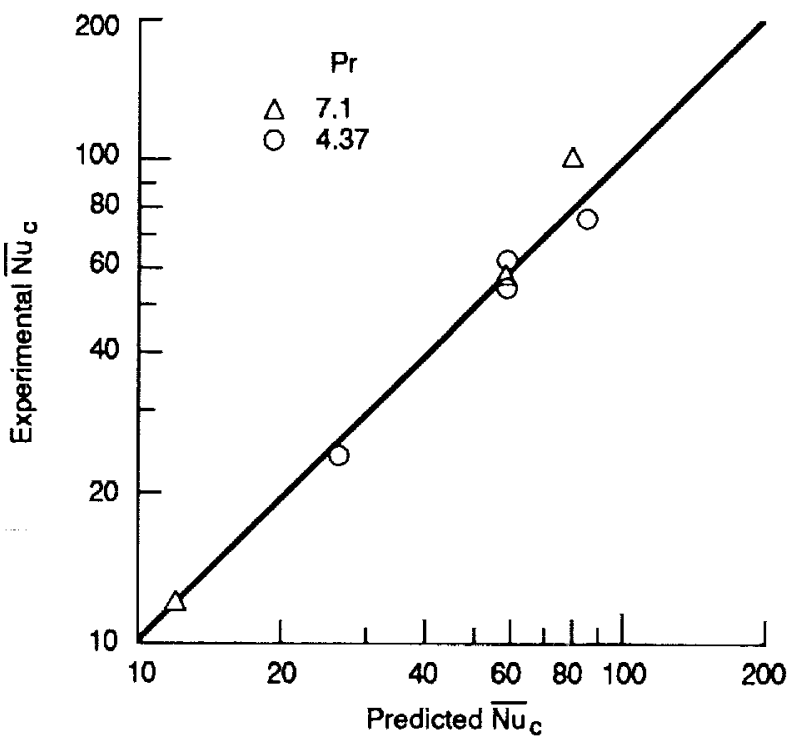

Figure 8.-Comparison of equation (22) with experiments of Ref. 7 . 


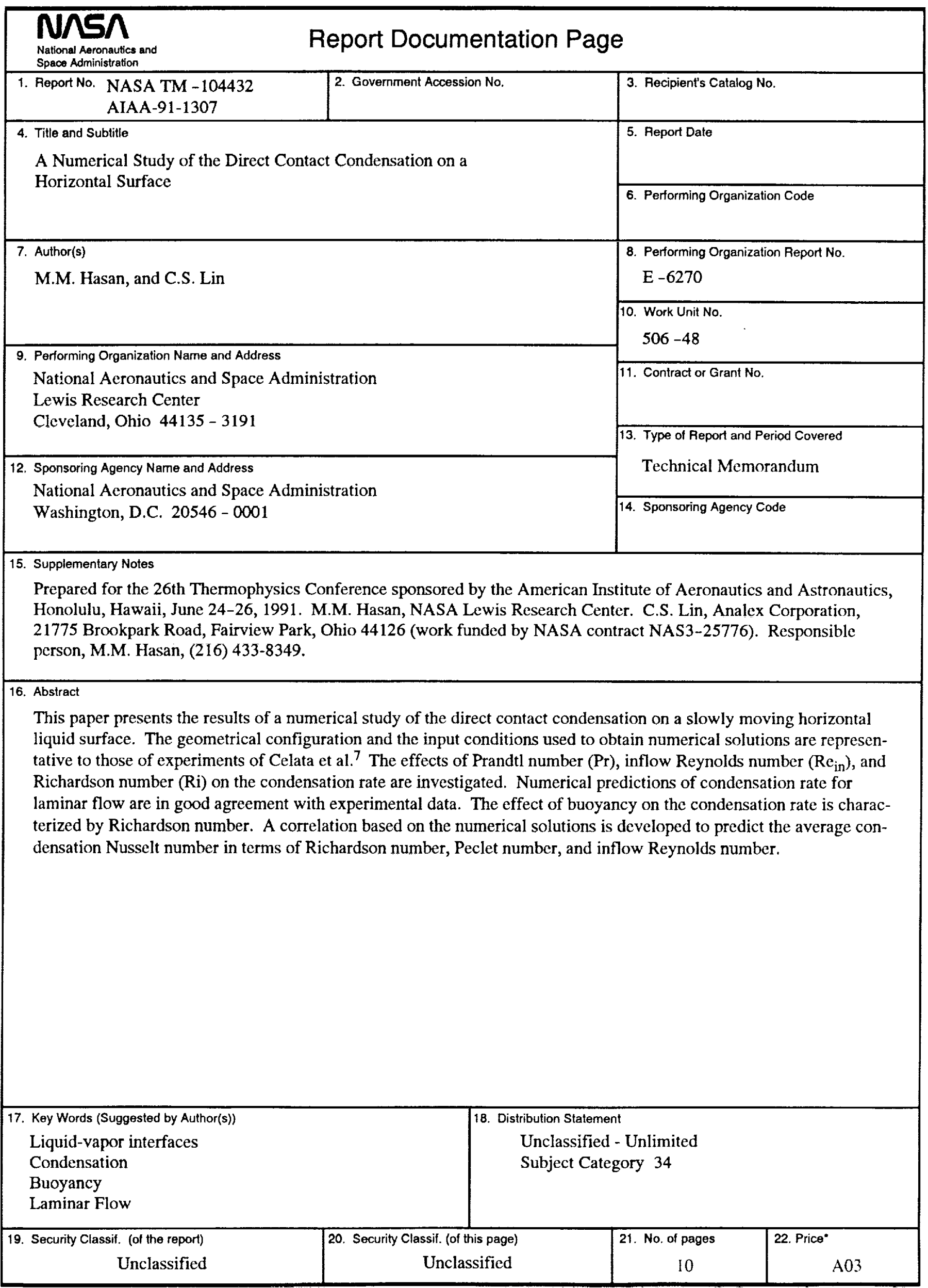

